\title{
ASSOCIATION OF SPORTS AND PHYSICAL ACTIVITY WITH OBESITY AMONG TEENAGERS IN POLAND
}

\section{BOŻENA GLINKOWSKA ${ }^{1}$ and WOJCIECH M. GLINKOWSKI ${ }^{2,3}$}

\author{
${ }^{1}$ Medical University of Warsaw, Warszawa, Poland \\ Department of Sports and Physical Education \\ ${ }^{2}$ Polish Telemedicine and eHealth Society, Warszawa, Poland \\ ${ }^{3}$ Medical University of Warsaw, Warszawa, Poland \\ Center of Excellence "TeleOrto" for Telediagnostics and Treatment of Injuries and Disorders of the Locomotor System
}

\begin{abstract}
Objectives: The purpose of the study was to assess the relationship between the body mass index and sports and physical activities in an unbiased, simple, random sample of teenagers from mid-northeastern Poland. Material and Methods: Children and adolescents aged 10-19 years old were surveyed. The Internet-based survey was conducted to collect information on physical activity, leisure time, studying hours, weight, and height. Results: Obesity was found to be low in the study population. The overall prevalence of overweight was not higher than $8 \%$. Only $0.6 \%$ of participants were underweight. Overall, $68 \%$ of them confirmed participating in sports. Boys were frequently more active than girls $(>70 \%$ boys and $>60 \%$ girls). Participants mostly played soccer, volleyball, handball, or basketball $(30.5 \%)$; $7 \%$ of them practiced martial arts and $16.5 \%$ of them participated in swimming. Sports activity significantly influenced body mass index. Obesity was not related to the lack of participation for physical activity in girls but a significant relationship was observed in boys $(p<0.02)$. The risk of obesity or overweight for inactive teenagers increased 2-fold $(p<0.01)$. Conclusions: We report the overall participation of teenagers from 2 cities in mid-northeastern Poland in sports and physical activities and demonstrate that the lack of statistically significant differences in the body mass index and obesity and overweight is prevalent among boys and girls. Obesity was significantly related to less physical activity in boys, and the likelihood of obesity or overweight increased in inactive teenagers. Thus, we suggest that the importance of overweight and obesity prevention programs should be emphasized. Int J Occup Med Environ Health 2018;31(6):771-782
\end{abstract}

Key words:

Survey, Sport, Overweight, Children and adolescents, Body mass index, Cross sectional

\section{INTRODUCTION}

Obesity and overweight among children and adolescents have become important and alarming public health problems globally. The common health problems related to obesity include type 2 diabetes mellitus (T2DM), hypertension, cardiovascular disease (CVD), arterial stiffening, dyslipidemia, liver dysfunction, respiratory and musculo- skeletal disorders, sub-fertility, renal failure, psychosocial problems, and certain types of oncological disorders [1-5]. Bouziotas et al. [6] studied the association between CVD risk factors (levels of high-density lipoprotein cholesterol, low-density lipoprotein cholesterol, triglycerides, the high-density lipoprotein-to-total cholesterol ratio, and systolic and diastolic blood pressure) and lifestyle param-

Funding: this work was supported by National Center for Research and Development (project No. NR13-0020-04/2008 entitled "Telemedical, automated system of three-dimensional measurement, analysis, detection, monitoring and treatment of defects and deformation of human body structure," project manager: Wojciech Glinkowski).

Received: December 10, 2016. Accepted: February 5, 2018.

Corresponding author: Wojciech M. Glinkowski, Polish Telemedicine and eHealth Society, Targowa 39a/5, 03-728 Warszawa, Poland (e-mail: w.glinkowski@gmail.com). 
eters (physical activity and overweight) among teenagers. Amongst children and adolescents, obesity-related complications may result in a decline in life expectancy and deteriorated quality of life [7-9].

Physical activity and fitness play an important role in preventing overweight and obesity among children and adolescents [10,11]. Reiner et al. [12] reported that physical activity had a long-term positive influence on weight gain, obesity, CVD, type 2 diabetes mellitus, Alzheimer's disease, and dementia. Cross-sectional and longitudinal studies on the relationships between physical activity, physical fitness, and overweight in early life reveal that approximately $25 \%$ of the adolescent population in several countries may be overweight or obese [13-18]. As few as 4 additional school-based physical education lessons per week may considerably improve the body composition of children aged 8-13 years old, reducing the prevalence of overweight and obesity among primary schoolchildren [19]. The impact of physical activity on the body mass index (BMI)/obese/overweight status is anticipated. Various factors may cause physical activity to differently influence BMI, including availability of daily attractions in the area of residence or obligatory or leisure activities. The authors considered it important to investigate this effect in a sample of Polish children/adolescents, especially because this association may vary among countries. The authors also wished to assess the physical activity and BMI levels in a young Polish population.

The aim of this study was to assess the relationship between BMI and sports and physical activities in an unbiased, random sample of teenagers residing in mid-northeastern Poland. We also evaluated the gross differences between residents of 2 cities, Warszawa and Ciechanów.

\section{MATERIAL AND METHODS}

\section{Study design}

We conducted a school-based cross-sectional study to determine the sports and physical activity level and nutritional status of children and adolescents aged 10-19 years old in selected cities of Mazovian Voivodeship in midnortheastern Poland.

\section{Study participants}

A total of 1364 participants were recruited from 10 randomly selected schools in Warszawa, the capital city of Poland (with approximately 1.7 million inhabitants), and additional 380 participants were recruited from 3 schools in Ciechanów (with approximately 46000 inhabitants). The main differences between these cities arise from physical and population sizes, access to sports and recreational facilities, and transportation systems.

The study was performed using an internet-based survey [20]. The study protocol adhered to the ethical standards of the Helsinki Declaration, and the Institutional Review Board (IRB) of the Medical University of Warsaw approved the study (No. KB 158/2009, issued August 25, 2009). Questionnaire links and consent forms were posted to the participating schools 2 weeks prior to data collection. The heads of the schools were contacted individually and were advised on the distribution of the questionnaires to parents and how to obtain consents. Class teachers contacted the parents or guardians of children and explained the procedure; the signed informed consent forms had been returned to the teachers before the children participated in the survey. The survey was unlocked for respondents only 2 weeks after the announcement at each school. Data was automatically collected by the survey system.

\section{Study questionnaire and variables}

The survey originally developed and validated by Korovessis et al. [21] for assessing physical activity, carrying of backpacks, and axial skeletal pain in schoolchildren and adolescents was translated into Polish and set up for safe distribution (guarded by a password) via the internet [20]. The survey, despite its main target, was adapted to assess physical activity and the body mass index (BMI) relationships. The survey consisted of 43 Likert-type rating scale items. 
The questionnaire included questions on duration spent on physical activity; leisure time activities; study hours; watching television; computer use; backpack/bag carrying; back pain; mood; posture; smoking habits; and personal questions about weight, height, age, school, and class.

The primary intention was to use the original survey translated into Polish. The survey was translated by a translation team, using extensive methodology, which consisted of several steps [22]. English items were translated into Polish by 2 native Polish-speaking, independent professional translators. The translators were instructed to use simple language, avoid any abbreviations, and to capture the meaning of the item. An independent, native Polishspeaking translator reconciled the 2 forward translations to create a single optimal version. The reconciled version was back-translated by a single native English-speaking translator, blinded to the English source version. The back-translation was then reviewed and compared to the source document, discrepancies were identified, and a clarified version was harmonized. The translated items and preceding translation steps were reviewed by medical and linguistic professionals. The pre-final version was then reviewed again. Finally, the translation coordinator, a native Polish-language speaker, approved the final translation by reviewing the translation histories of all items and refining each item. The final version was formatted, typeset, and proofread. The local educational authorities reviewed the final survey and insisted that some changes pertaining to pain behavior and menarche, neither of which were analyzed in this study, and thus did not affect this study's primary goals, be made. Once these modifications were made, the survey items were approved.

The survey system allowed the researchers to send a link to the participants, enabling them to upload or enter the survey items through a web browser. Logging in to the survey required a password that was only made available to students when they were at their schools. All sensitive personal information was excluded from the survey. The participants completed the questionnaire by themselves, without the help of their peers or parents in the computer classroom. The individual response was assured by the teacher who did not interfere in the survey, but was present in the classroom. Weight and height data was available from the school nurses who had recently performed the annual obligatory examinations.

Representative items included in the questionnaire were as follows: "How many hours do you watch TV during the day?;" "How many hours a day do you spend at the computer/game console (learning/playing games)?;" "How many hours of the day do you spend studying, reading books/magazines, etc.?;" "How many hours of the day do you spend at school (including extracurricular activities, such as language learning, tutoring, etc.)?;" "How many hours a week do you take part in physical exercises? (any form of physical activity, including corrective gymnastics and rehabilitation);" "For how many years have you practiced your physical/sports activity?;" "How many times a week do you have sports training?," etc.

The body mass index was calculated as the ratio of weight in kilograms and the square of height in meters. Age- and sex-specific point estimates of the prevalence of overweight (including obesity) and obesity were calculated together with the $95 \%$ confidence interval (CI) of the estimates according to the International Obesity Task Force definition and the World Health Organization (WHO) [23]. Cut-off values for BMI-for-age (5-19 years old) were interpreted according to the WHO: overweight: $>+1$ standard deviation (SD) (equivalent to BMI $25 \mathrm{~kg} / \mathrm{m}^{2}$ at 19 years old); obesity: > +2 SD (equivalent to BMI $30 \mathrm{~kg} / \mathrm{m}^{2}$ at 19 years old $)$; thinness: $<-2 \mathrm{SD}\left(<18.49 \mathrm{~kg} / \mathrm{m}^{2}\right.$ at 19 years old $)$ $[24,25]$.

\section{Statistical analysis}

All statistical analyses were performed using SAS 9.3 (SAS Institute Inc., Cary, NC, USA). The body mass index z-scores were calculated as the measures of relative 
weight, adjusted for the child's age and sex. For each child, BMI z-scores and percentiles were calculated, using the 2000 version of the US Centers for Disease Control and Prevention (CDC) Growth Charts [26]. The analyses were performed for all participants, classified according to sex, athlete status, and city. The Kruskal-Wallis test, Fisher's exact test, Mann-Whitney U test, and Chi ${ }^{2}$ test were used where appropriate, and descriptive statistics were prepared. The Kruskal-Wallis test was used for testing whether the mean ranks were the same for the data in all the participant groups. The Mann-Whitney U test was applied to test whether the observations from both groups were independent of each other and whether the probability of an observation from the population of boys and girls from one city exceeded that from the second city. Fisher's exact test was used for nominal variables, to determine whether the proportions of variables in Warszawa and Ciechanów were different. A p-value of $<0.05$ was considered significant.

\section{RESULTS}

A total of 1744 children and adolescents, aged 10-19 years old, were surveyed; the sample included 907 (52\%) girls and 837 (48\%) boys. The participants from Ciechanów were considerably younger than those from Warszawa (median: 13.55 vs. 14.35 years, Kruskal-Wallis test $=30.33$; $\mathrm{p}<0.0001)$.

Among 907 girls participating in the study, 687 (75.7\%) were from Warszawa and $220(24.3 \%)$ were from Ciechanów. Among 837 boys, 677 (80.9\%) were from Warszawa and 160 (19.1\%) were from Ciechanów. The height, weight, and the BMI values of all participants are presented in the Table 1.

The data was not normally distributed. The prevalence of thinness, normal weight, overweight, and obesity are presented in the Table 2. Thin, normal, and obese participants did not differ significantly between Warszawa and Ciechanów (Fisher's exact test $=0.0217 ; \mathrm{p}=0.2892$ ) .
Table 1. Characteristics of Warszawa and Ciechanów respondents of the modified questionnaire for the assessment of back pain in children and adolescents (Dec 13, 2011-May 11, 2013)

\begin{tabular}{lccc}
\hline Variable & Me & Min. & Max \\
\hline $\begin{array}{l}\text { Weight } \\
\text { Warszawa } \\
\text { girls }\end{array}$ & & & \\
boys & 69.0 & 25.0 & 120.0 \\
Ciechanów & & 25.0 & 122.0 \\
$\quad$ girls & 50.0 & 24.0 & 92.0 \\
$\quad$ boys & 56.0 & 25.0 & 121.0 \\
Height & & & \\
Warszawa & & & \\
$\quad$ girls & 162.0 & 132.0 & 190.0 \\
boys & 172.0 & 127.0 & 200.0 \\
Ciechanów & & & \\
girls & 160.0 & 124.0 & 185.0 \\
$\quad$ boys & 168.0 & 137.0 & 190.0 \\
BMI & & & \\
Warszawa & & & \\
girls & 18.9 & 11.4 & 45.2 \\
boys & 20.3 & 8.5 & 44.8 \\
Ciechanów & & & \\
girls & 19.1 & 13.0 & 35.0 \\
boys & 20.2 & 11.7 & 39.0 \\
\hline
\end{tabular}

Me - median; min. - minimal value; max - maximal value.

A higher proportion of extremely obese participants was observed in Warszawa. A significantly higher proportion of overweight participants was observed in Ciechanów, particularly among girls $\left(\mathrm{Chi}^{2}(3)=9.2 ; \mathrm{p}=0.027\right.$ ) (when obese subjects were not included). The mean BMI percentile of boys (51.2) was significantly higher than that of girls (43.9) $(\mathrm{p}<0.0001)$. The mean BMI percentile was 46.5 for youth from Warszawa and 50.7 for youth from Ciechanów $\left(\mathrm{Chi}^{2}=5.85 ; \mathrm{p}=0.0156\right)$.

The median BMI z-score in boys from Warszawa and Ciechanów was 0.027 and 0.25 , respectively. The me- 
Table 2. The prevalence of variables for Warszawa and Ciechanów respondents of the modified questionnaire for the assessment of back pain in children and adolescents (Dec 13, 2011-May 11, 2013)

\begin{tabular}{|c|c|c|c|c|c|}
\hline \multirow[t]{2}{*}{ Respondents } & \multicolumn{5}{|c|}{$\begin{array}{c}\text { Weight range } \\
{[\mathrm{n}(\%)]}\end{array}$} \\
\hline & thinness & normal & overweight & obesity & total \\
\hline \multicolumn{6}{|l|}{ Girls } \\
\hline Warszawa & $292(42.50)$ & $365(53.13)$ & $19(2.77)$ & $11(1.60)$ & 687 \\
\hline Ciechanów & $94(42.73)$ & $101(45.91)$ & $24(10.91)$ & $1(0.45)$ & 220 \\
\hline \multicolumn{6}{|l|}{ Boys } \\
\hline Warszawa & $207(30.58)$ & $395(58.35)$ & $53(7.83)$ & $22(3.25)$ & 677 \\
\hline Ciechanów & $50(31.25)$ & $96(60.00)$ & $10(6.25)$ & $4(2.50)$ & 160 \\
\hline
\end{tabular}

dian scores for girls were -0.11 in Warszawa and -0.16 in Ciechanów. The differences were not statistically significant $\left(\mathrm{Chi}^{2}(2)=1.21 ; \mathrm{p}=0.545\right)$. The Figure 1 illustrates cross-sectional differences of the median z-scores of the study cohort.

Participants from Warszawa spent more time at school and less time playing computer games or watching television than participants from Ciechanów (Table 3). Moreover, they devoted more time to physical activity, according to self-reported data. Overall, $68 \%$ of the participants

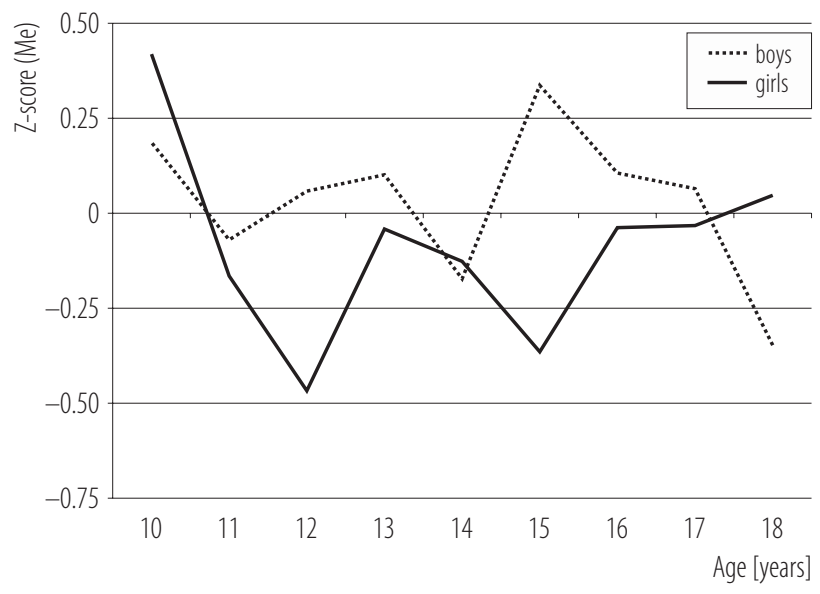

Fig. 1. The median body mass index z-scores of the study cohort (adolescent growth spurts typically influence the body mass index z-scores for both sexes, for girls at the age of 11-12 years old and 14-15 years, and for boys at the age of 13-14 years old and 16-18 years old)
$(\mathrm{N}=1187)$ declared that they were active in sports (equal in both cities: Warszawa $-69 \%$ and Ciechanów - 66\%). Boys in both cities were more involved in sports activities than the girls: Warszawa, $72.8 \%(\mathrm{~N}=493)$ boys vs. $64.6 \%$ $(\mathrm{N}=444)$ girls participated in sports; Ciechanów, 73.8\% $(\mathrm{N}=118)$ boys vs. $60 \%(\mathrm{~N}=132)$ girls engaged in sports. Overall, $30.5 \%$ of participants played soccer, volleyball, handball, or basketball; $7 \%$ of them participated in mar-

Table 3. The daily schedules of respondents of the modified questionnaire for the assessment of back pain in children and adolescents (Dec 13, 2011-May 11, 2013)*

\begin{tabular}{lc}
\hline \multicolumn{1}{c}{ Activity } & Time \\
\hline Watching TV, computer and reading $[\mathrm{h}]$ & \\
Warszawa & 6.30 \\
Ciechanów & 6.50 \\
School [h] & \\
Warszawa & 7.40 \\
Ciechanów & 7.06 \\
Physical exercises [h/week] & \\
Warszawa & 4.20 \\
Ciechanów & 3.70 \\
\hline
\end{tabular}

* Including: time spent watching television, using the computer, and reading on a daily basis (Mann-Whitney $\mathrm{U}$ test $\mathrm{Z}=2.9 ; \mathrm{p}=0.0034$ ); school hours daily (Mann-Whitney $\mathrm{U}$ test $\mathrm{Z}=-5.4 ; \mathrm{p}<0.0001$ ); weekly physical activity hours (Mann-Whitney $\mathrm{U}$ test $\mathrm{Z}=-4.2$; $\mathrm{p}<0.0001$ ) 
tial arts training; $16.5 \%$ of them engaged in swimming; and $46 \%$ of them did not specify the sports discipline in which they were involved. The disciplines were determined based on the participants' description, assuming the principal discipline to be the first one described (tennis, dancing, horse riding, athletics, fitness training, and others). Participants from Ciechanów played soccer, volleyball, handball, or basketball more commonly than their peers from Warszawa (36\% vs. 29.2\%), but selected swimming less frequently (11.6\% vs. $17.93 \%)$. These differences were statistically significant $(\mathrm{p}=0.0018)$.

The frequency of training sessions per week is presented in the Table 4. Most participants underwent short training sessions. In the participants from Warszawa, involvement in sports activities was significantly associated with BMI. The mean BMI was $20.3 \mathrm{~kg} / \mathrm{m}^{2}$ for boys engaging in sports compared to a mean of $21.5 \mathrm{~kg} / \mathrm{m}^{2}$ for those not engaging in sports (Kruskal-Wallis test $=9.06 ; \mathrm{p}=0.0026$ ). For girls, the corresponding values were $19.1 \mathrm{~kg} / \mathrm{m}^{2}$ and $19.7 \mathrm{~kg} / \mathrm{m}^{2}$, respectively (Kruskal-Wallis test $=6.43$; $\mathrm{p}=0.0112$ ). These differences were not statistically significant in participants from Ciechanów (mean BMI of girls engaging in sports was $19.8 \mathrm{~kg} / \mathrm{m}^{2}$ compared to $19.4 \mathrm{~kg} / \mathrm{m}^{2}$

Table 4. Training sessions attended by respondents of the modified questionnaire for the assessment of back pain in children and adolescents (Dec 13, 2011-May 11, 2013)

\begin{tabular}{lrc}
\hline \multirow{2}{*}{$\begin{array}{c}\text { Training } \\
\text { sessions } \\
{[\mathrm{n} / \text { week }]}\end{array}$} & \multicolumn{2}{c}{$\begin{array}{c}\text { Children and adolescents attending trainings } \\
{[\mathrm{n}(\%)]}\end{array}$} \\
\cline { 2 - 3 } 1 & Warszawa & Ciechanów \\
2 & $82(11.7)$ & $24(9.8)$ \\
3 & $190(27.1)$ & $56(22.8)$ \\
4 & $151(21.5)$ & $74(30.0)$ \\
5 & $104(14.8)$ & $46(18.7)$ \\
6 & $71(10.1)$ & $22(8.9)$ \\
$>6$ & $56(8.0)$ & $22(8.9)$ \\
Total & $47(6.7)$ & $2(0.8)$ \\
\hline
\end{tabular}

for those not engaging in sport; for boys these values were $20.4 \mathrm{~kg} / \mathrm{m}^{2}$ and $21.1 \mathrm{~kg} / \mathrm{m}^{2}$, respectively). These values for boys and girls fall within a normal, healthy BMI category, which may make the observed differences clinically nonsignificant. There was no significant relationship between involvement in sports activities and obesity and their lack among girls, but a significant relationship was observed for boys, although only in the Warszawa group $\left(\mathrm{Chi}^{2}(3)=10.95 ; \mathrm{p}=0.012\right)$. The chance of being obese or overweight in boys who self-reported lack of participation in physical or sports activities was twice that of active boys (odds ratio $=2 ; 95 \% \mathrm{CI}: 1.3-3.3 ; \mathrm{p}=0.0013$ ). The sample size from Ciechanów was too small to allow a valid assessment. However, among boys, obesity was significantly associated with a lack of engagement in sports activities $\left(\mathrm{Chi}^{2}(3)=11.4 ; \mathrm{p}=0.0099\right)$.

\section{DISCUSSION}

In this study, we assessed the relationship between BMI and sports and physical activities in an unbiased, simple random sample of teenagers residing in mid-northeastern Poland. We observed no significant differences in BMI values and obesity and overweight prevalence among boys and girls from Warszawa and Ciechanów. The incidences of overweight and obesity were less alarming than expected in the studied regions and were also lower than those reported in other countries. Obesity was significantly related to sports activities in boys $(\mathrm{p}<0.02)$ but not in girls, and the overall risk of obesity or overweight in inactive teenagers increased 2-fold $(\mathrm{p}<0.01)$.

An increased prevalence of overweight and obesity in children is associated with high mortality rates related to coronary heart disease (CHD) in adulthood [12]. Moreover, Soares Ferreira et al. [27], in a study in Portugal, reported that a high prevalence of overweight and central adiposity was associated with low physical activity and fitness levels. The prevalence of overweight and obesity was $23.5 \%$ and $5.4 \%$, respectively, in boys, 
and $21.4 \%$ and $3.4 \%$, respectively, in girls, during the ages of 12-17 years old. The prevalence of overweight and obesity in Portuguese children and adolescents was 8.3$27.4 \%$ for boys and $13.4-35 \%$ for girls, based on the CDC criteria, and was $21.1-22.1 \%$ for boys and $19.7-31.3 \%$ for girls, based on the WHO criteria [28]. In Poland [23], the prevalence of obesity varied: $5.9-26 \%$ in males and 6.1-21.3\% in females, according to the CDC criteria, and 4.4-22.9\% for males and 3.8-8.2\% for females, according to the WHO criteria.

Previously, it was reported that the median BMI z-scores were positive for men and for early childhood and decreased with age [23]. This tendency was also observed in this study for males aged $\geq 15$ years old and among the population aged 10-19 years old. In addition, BMI z-scores decreased during the process of growth in both sex groups. The median BMI z-scores, calculated with the use of the Łódź reference, fluctuated between 0.05 and 0.2 over the studied age range. In this study, the body weights of the current study groups were compared with those of other Polish studies. Overall, the BMI z-scores of the children in this study population were lower than those reported in children from the central region of Poland [23,29].

Higher levels of self-reported physical activity lead to lower body weight or a more favorable distribution of body fat [30]. In 2013, Ortega et al. [13] confirmed that high levels of physical activity during childhood and adolescence, particularly involvement in sports activities, decreased total and central adiposity later in life, and suggested that increasing the rates of physical fitness in overweight children and adolescents may have many positive effects on health. The fitness and activity levels of the adolescent population may be tested using the Adolescents and Surveillance System for the Obesity prevention - Fitness Test Battery (ASSO-FTB) [31], a tool developed within the Adolescents and Surveillance System for the Obesity prevention project [32] to allow teachers and school-related workers to assess the physical fitness of adolescents over time, and thereby, to help prevent obesity and its related diseases. Rauner et al. [33] also reported that overweight and obesity were inversely related to physical activity. However, it remained unclear whether excessive body weight was the cause or the effect of low levels of exercise and fitness.

The strength of the association between sports/physical activity and BMI may vary among countries. In the United States, Morrow et al. [34] observed that adolescents who failed to meet the national aerobic and muscle-strengthening exercise guidelines had higher odds of not achieving healthy physical fitness levels of aerobic capacity, BMI, muscle fitness, and the combination of all these. On the other hand, Vella et al. [35], in a large nationally representative sample of Australian adolescents, observed no association between participation in organized sports and the likelihood of overweight or obesity. Pérez et al. [36] investigated differences in the association between physical activity and overweight among students living in 2 adjacent areas on either side of Mexico-US border. Adolescent boys who participated in sports teams were less likely to be at or above the 85th percentile of BMI for age and sex [36]. Ostojic et al. [37] pointed out a high prevalence of adiposity among Serbian schoolchildren aged 6-14 years old, with a strong negative relationship between aerobic fitness and adiposity. Al-Nakeeb et al. [38] noted significant differences in the percentages of overweight/obesity and the levels of physical activity in adults in the United Kingdom and Saudi Arabia, with men being more physically active than women. These findings highlight the diverse lifestyles of young people living in different parts of the world.

Moreover, in Brazil, Greguol et al. [39] detected significant correlations $(\mathrm{p}>0.05)$ between physical activity and the perception of body image and BMI. Wang et al. [40], who studied the association between physical activity, BMI level, and mental health among Chinese adolescent cohorts (aged 11-13 years old), observed that $58.1 \%$ performed insufficient physical activity: $18.4 \%$ were overweight and $16 \%$ were obese. Insuffi- 
cient physical activity was positively associated with anxiety and depression, and obesity was positively associated with depression. Wong and Leatherdale [41], in a study of children attending secondary schools in Ontario, Canada, showed that boys with low activity-high sedentary lifestyle were more likely to be overweight than those with high activity-low sedentary lifestyle. Girls, those with high activity-low sedentary lifestyle were less likely to be overweight, in contrast to those with a low activity-high sedentary or high activity-high sedentary lifestyle. In a study among rural South African adolescents aged 11-12 years old and 14-15 years old, Micklesfield et al. [42] found that socio-economic status at the maternal, household, and community level independently predicted the time spent on sedentary behaviors, and on moderate-vigorous weekly school- and club-based physical activities. In southeastern Brazil, de Pinho et al. [43] reported that overweight was prevalent for $18.5 \%$ of adolescents; factors associated with weight excess included the lack of engaging in sports activities during leisure time.

Some countries have developed guidelines for preventative measures against obesity, including physical activity $[34,44]$. Policies to increase physical activity levels in schools have been implemented in many regions. Prevention strategies should concentrate on stressing the importance of physical activity early in life, to diminish the increased prevalence of adult CVD-related mortality [6]. However, the recommended physical activity model is not well delineated in the literature. Drake et al. [45] concluded that participation in team sports had the strongest and most consistent inverse association with weight status. The authors observed that an active commute to school may reduce the risk of obesity, but not necessarily that of being overweight.

Tremblay et al. [46] determined the relationship between sedentary behavior and health indicators in school-aged children and adolescents aged 5-17 years old. Watching television was the most common measure of sedentary behavior and body composition was the most common outcome measure. Qualitative analyses of all the studies revealed a dose-response relationship between increased sedentary behavior and unfavorable health outcomes. Spending $>2 \mathrm{~h} /$ day watching television was associated with unfavorable body composition, decreased fitness levels, lowered scores for self-esteem and pro-social behavior, and decreased levels of academic achievement [46]. Data from this study showed that teenagers spent a considerable amount of time (6.3-6.5 h/day) engaging in sedentary activities (watching television, engaging in computer-related activities, and reading).

This study had some limitations. We adopted a survey instrument that was originally focused on physical activity and axial musculoskeletal problems for a cross-sectional evaluation of the associations of sports and physical activity with BMI among teenagers in mid-northeastern Poland [21]. Although the set of questions met the criteria of the study, the modified protocol was not originally designed to test nutritional status. The findings are based on self-reported data; hence, inaccuracies may exist. Subjects declared their weight and height based on their best knowledge of recent measurements. Values used for calculating BMI, and related measures were not measured by investigators using reliable stadiometry, and a medical scale was used in the study $[23,47,48]$. Finally, the participants responded to the survey alone at school, without parental supervision; this may have introduced various biases. In addition, the exactness and accuracy of the self-reported number of hours and number of sessions of sports activities were not verified.

However, a strength of our study is that it provides an overview of the burden of childhood obesity among a representative sample of children and adolescents aged 1019 years old in a region of Poland. These findings may be used as a benchmark for future comparisons by public health personnel and policymakers, using a simple and easy-to-use survey instrument. This may facilitate further 
research on childhood obesity prevention and could be used to monitor future trends, considering the alarming rise in the global prevalence of diabetes and hypertension.

\section{CONCLUSIONS}

We surveyed the participation of teenagers from 2 cities in Poland in sports and physical activities, and assessed its impact on overweight and obesity. The lack of statistically significant differences in the BMI z-scores of boys and girls from Warszawa and Ciechanów indicate that obesity and overweight are equally distributed among participants in these cities of mid-north-east Poland. The overall prevalence of overweight was not higher than $8 \%$. The prevalence of obesity was slightly higher in Warszawa than in Ciechanów, suggesting that the local environment and lifestyle factors exert some influence. Obesity was significantly related to sports activities in boys but not in girls, and the risk of obesity or overweight in inactive teenagers overall increased 2-fold. We observed a positive trend for engagement in physical activity; however, a significantly higher proportion of teenagers of both sexes participated in short (rather than long) training sessions, which may be inadequate to considerably influence BMI. The incidences of overweight and obesity were less alarming than expected in the studied regions and were observed to be lower than those reported in other countries. Despite the observed results, the importance of overweight and obesity prevention programs should be emphasized. Further, cyclic studies should be conducted to investigate how the expansion of digital changes of life influences overweight and obesity prevalence and physical activity habits among school children and adolescents.

\section{ACKNOWLEDGMENTS}

Authors thanks to Mrs. Izabela Czyżak for her statistical analysis support.

We would like to thank Editage (http:/www.editage.com) for editing and reviewing this manuscript for the English language.

\section{REFERENCES}

1. Williams R, Alexander G, Armstrong I, Baker A, Bhala N, Camps-Walsh G, et al. Disease burden and costs from excess alcohol consumption, obesity, and viral hepatitis: Fourth report of the Lancet Standing Commission on Liver Disease in the UK. Lancet. 2018;391(10125):1097-107, https://doi. org/10.1016/S0140-6736(17)32866-0.

2. Djalalinia S, Qorbani M, Peykari N, Kelishadi R. Health impacts of obesity. Pak J Med Sci. 2015;31(1):239-42, https:// doi.org/10.12669/pjms.311.7033.

3. Lee YS. Consequences of childhood obesity. Ann Acad Med Singapore. 2009;38(1):75-7.

4. Kelishadi R. Childhood overweight, obesity, and the metabolic syndrome in developing countries. Epidemiol Rev. 2007;29(1):62-76, https://doi.org/10.1093/epirev/mxm003.

5. Daniels SR. Complications of obesity in children and adolescents. Int J Obes (Lond). 2009;33 Suppl 1:S60-5, https://doi. org/10.1038/ijo.2009.20.

6. Bouziotas C, Koutedakis Y, Nevill A, Ageli E, Tsigilis N, Nikolaou A, et al. Greek adolescents, fitness, fatness, fat intake, activity, and coronary heart disease risk. Arch Dis Child. 2004;89(1):41-4.

7. Arteburn DE. Obesity in children. BMJ Clin Evid. 2007;2007:0325.

8. Fichna P, Skowronska B. [Obesity related complications in children and adolescents]. Endokrynol Diabetol Chor Przemiany Materii Wieku Rozw. 2006;12(3):223-8. Polish.

9. Fichna P, Skowrońska B, Majewska K, Stankiewicz W. Early impairment of glucose tolerance and beta-cell function in obese children. Pediatr Endocrinol Diabetes Metab. 2010;16(4):255-61.

10. Nock NL, Ievers-Landis CE, Dajani R, Knight D, Rigda A, Narasimhan S, et al. Physical activity self-efficacy and fitness: Family environment relationship correlates and selfesteem as a mediator among adolescents who are overweight or obese. Child Obes. 2016;12(5):360-7, https://doi. org/10.1089/chi.2016.0007. 
11. Ardelt-Gattinger E, Ring-Dimitriou S, Hofmann J, Paulmichl K, Zsoldos F, Weghuber D. [Gender differences of psychological, nutritional, and physical fitness variables influencing obesity/overweight in Austrian children and adolescents]. Wien Med Wochenschr. 2016;166(3-4):111-6, https://doi.org/10.1007/s10354-015-0427-9. German.

12. Reiner M, Niermann C, Jekauc D, Woll A. Long-term health benefits of physical activity - A systematic review of longitudinal studies. BMC Public Health. 2013;13:813, https:/doi. org/10.1186/1471-2458-13-813.

13. Ortega FB, Ruiz JR, Castillo MJ. Physical activity, physical fitness, and overweight in children and adolescents: Evidence from epidemiologic studies. Endocrinol Nutr. 2013;60(8): 458-69, https://doi.org/10.1016/j.endonu.2012.10.006.

14. Freedman DS, Lawman HG, Skinner AC, McGuire LC, Allison DB, Ogden CL. Validity of the WHO cutoffs for biologically implausible values of weight, height, and BMI in children and adolescents in NHANES from 1999 through 2012. Am J Clin Nutr. 2015;102(5):1000-6, https://doi.org/10.3945/ ajcn.115.115576.

15. Ogden CL, Carroll MD, Kit BK, Flegal KM. Prevalence of obesity and trends in body mass index among US children and adolescents, 1999-2010. JAMA. 2012;307(5):483-90, https://doi.org/10.1001/jama.2012.40.

16. Ogden CL, Carroll MD, Curtin LR, Lamb MM, Flegal KM. Prevalence of high body mass index in US children and adolescents, 2007-2008. JAMA. 2010;303(3):242-9, https://doi. org/10.1001/jama.2009.2012.

17. Mi J, Cheng H, Hou DQ, Duan JL, Teng HH, Wang YF. [Prevalence of overweight and obesity among children and adolescents in Beijing in 2004]. Zhonghua Liu Xing Bing Xue Za Zhi. 2006;27(6):469-74.

18. Ko GT, Ozaki R, Wong GW, Kong AP, So WY, Tong PC, et al. The problem of obesity among adolescents in Hong Kong: A comparison using various diagnostic criteria. BMC Pediatr. 2008;8:10, https://doi.org/10.1186/1471-2431-8-10.

19. Klakk H, Chinapaw M, Heidemann M, Andersen LB, Wedderkopp N. Effect of four additional physical education lessons on body composition in children aged 8-13 years A prospective study during two school years. BMC Pediatr. 2013;13:170, https://doi.org/10.1186/1471-2431-13-170.

20. Łukasik B, Glinkowski W, Marasek K. The development of Web-based surveying platform for eHealth and clinical telemedicine. In: Jordanova M, Lievens F, editors. Med-e-Tel 2012, Electronic proceedings of The International eHealth, Telemedicine and Health ICT Forum for Educational, Networking and Business; 2012 Apr 18-20; Luxembourg, G.D. of Luxembourg. Grimbergen: International Society for Telemedicine \& eHealth (ISfTeH); 2012. p. 708-11.

21. Korovessis P, Koureas G, Papazisis Z. Correlation between backpack weight and way of carrying, sagittal and frontal spinal curvatures, athletic activity, and dorsal and low back pain in schoolchildren and adolescents. J Spinal Disord Tech. 2004;17(1):33-40, https://doi.org/10.1097/00024720200402000-00008.

22. Gomez-Calvente M, Medina-Porqueres I, Fontalba-Navas A, Pena-Andreu JM, de Vos-Martin C. Validation and cross-cultural adaptation of the "Fibromyalgia Participation Questionnaire" to the Spanish population: Study protocol. Rheumatol Int. 2015;35(9):1609-13, https://doi.org/10.1007/ s00296-015-3262-9.

23. Kulaga Z, Litwin M, Tkaczyk M, Różdżynska A, Barwicka K, Grajda A, et al. The height-, weight-, and BMI-for-age of Polish school-aged children and adolescents relative to international and local growth references. BMC Public Health. 2010;10:109, https://doi.org/10.1186/1471-2458-10-109.

24. Butte NF, Garza C, de Onis M. Evaluation of the feasibility of international growth standards for school-aged children and adolescents. J Nutr. 2007;137(1):153-7, https://doi. org/10.1093/jn/137.1.153.

25. De Onis M, Lobstein T. Defining obesity risk status in the general childhood population: Which cut-offs should we use? Int J Pediatr Obes. 2010;5(6):458-60, https://doi. org/10.3109/17477161003615583.

26. Kuczmarski RJ, Ogden CL, Guo SS, Grummer-Strawn LM, Flegal KM, Mei Z, et al. 2000 CDC Growth Charts for the 
United States: Methods and development. Vital Health Stat 11. 2002;(246):1-190.

27. Soares Ferreira F, Ramos Duarte JA. Overweight, obesity, physical activity, cardiorespiratory and muscular fitness in a Portuguese sample of high school adolescents. Minerva Pediatr. 2013;65(1):83-91.

28. Antunes A, Moreira P. [Prevalence of overweight and obesity in Portuguese children and adolescents]. Acta Med Port. 2011;24(2):279-84, Portuguese.

29. Kułaga Z, Litwin M, Tkaczyk M, Palczewska I, Zajączkowska M, Zwolińska D, et al. Polish 2010 growth references for school-aged children and adolescents. Eur J Pediatr. 2011;170(5):599-609, https://doi.org/10.1007/s00431-0101329-x.

30. DiPietro L. Physical activity, body weight, and adiposity: An epidemiologic perspective. Exerc Sport Sci Rev. 1995;23:275303, https://doi.org/10.1249/00003677-199500230-00011.

31. Bianco A, Mammina C, Jemni M, Filippi AR, Patti A, Thomas E, et al. A Fitness Index model for Italian adolescents living in Southern Italy: The ASSO project. J Sports Med Phys Fitness. 2016;56(11):1279-88.

32. Bianco A, Jemni M, Thomas E, Patti A, Paoli A, Ramos Roque J, et al. A systematic review to determine reliability and usefulness of the field-based test batteries for the assessment of physical fitness in adolescents - The ASSO Project. Int J Occup Med Environ Health. 2015;28(3):445-78, https://doi.org/10.13075/ijomeh.1896.00393.

33. Rauner A, Mess F, Woll A. The relationship between physical activity, physical fitness and overweight in adolescents: A systematic review of studies published in or after 2000. BMC Pediatr. 2013;13:19, https://doi.org/10.1186/14712431-13-19.

34. Morrow JR Jr., Tucker JS, Jackson AW, Martin SB, Greenleaf CA, Petrie TA. Meeting physical activity guidelines and health-related fitness in youth. Am J Prev Med. 2013;44(5): 439-44, https://doi.org/10.1016/j.amepre.2013.01.008.

35. Vella SA, Cliff DP, Okely AD, Scully ML, Morley BC. Associations between sports participation, adiposity and obesity-related health behaviors in Australian adolescents. Int J Behav Nutr Phys Act. 2013;10:113, https://doi. org/10.1186/1479-5868-10-113.

36. Perez A, Reininger BM, Aguirre Flores MI, Sanderson M, Roberts RE. Physical activity and overweight among adolescents on the Texas-Mexico border. Rev Panam Salud Publica. 2006;19(4):244-52, https://doi.org/10.1590/S102049892006000400004.

37. Ostojic SM, Stojanovic MD, Stojanovic V, Maric J, Njaradi N. Correlation between fitness and fatness in 6-14-year old Serbian school children. J Health Popul Nutr. 2011;29(1): 53-60.

38. Al-Nakeeb Y, Lyons M, Collins P, Al-Nuaim A, Al-Hazzaa H, Duncan MJ, et al. Obesity, physical activity and sedentary behavior amongst British and Saudi youth: A cross-cultural study. Int J Environ Res Public Health. 2012;9(4):1490-506, https://doi.org/10.3390/ijerph9041490.

39. Greguol M, Gobbi E, Carraro A. Physical activity practice, body image and visual impairment: A comparison between Brazilian and Italian children and adolescents. Res Dev Disabil. 2014;35(1):21-6, https://doi.org/10.1016/j. ridd.2013.10.020.

40. Wang H, Fu J, Lu Q, Tao F, Hao J. Physical activity, body mass index and mental health in Chinese adolescents: A population based study. J Sports Med Phys Fitness. 2014;54(4):518-25.

41. Wong SL, Leatherdale ST. Association between sedentary behavior, physical activity, and obesity: Inactivity among active kids. Prev Chronic Dis. 2009;6(1):A26.

42. Micklesfield LK, Pedro TM, Kahn K, Kinsman J, Pettifor JM, Tollman S, et al. Physical activity and sedentary behavior among adolescents in rural South Africa: Levels, patterns and correlates. BMC Public Health. 2014;14:40, https://doi.org/10.1186/1471-2458-14-40.

43. De Pinho L, Botelho AC, Caldeira AP. Associated factors of overweight in adolescents from public schools in Northern Minas Gerais State, Brazil. Rev Paul Pediatr. 2014;32(2): 237-43, https://doi.org/10.1590/0103-0582201432216213. 
44. Block JP, Oken E. Practical considerations for the US Preventive Services Task Force recommendations on obesity in children and adolescents. JAMA Intern Med. 2017;177(8): 1077-9, https://doi.org/10.1001/jamainternmed.2017.1978.

45. Drake KM, Beach ML, Longacre MR, Mackenzie T, Titus LJ, Rundle AG, et al. Influence of sports, physical education, and active commuting to school on adolescent weight status. Pediatrics. 2012;130(2):e296-304, https://doi. org/10.1542/peds.2011-2898.

46. Tremblay MS, LeBlanc AG, Kho ME, Saunders TJ, Larouche R, Colley RC, et al. Systematic review of sedentary behaviour and health indicators in school-aged children and youth. Int J Behav Nutr Phys Act. 2011;8:98, https://doi. org/10.1186/1479-5868-8-98.

47. Ghosh A. Association of anthropometric, body composition and physiological measures with physical activity level among the children and adolescents of Asian Indian origin: The Calcutta obesity study. J Nutr Health Aging. 2010;14(9):731-5, https://doi.org/10.1007/s12603-010-0096-8.

48. Mihas C, Mariolis A, Manios Y, Naska A, Panagiotakos D, Arapaki A, et al. Overweight/obesity and factors associated with body mass index during adolescence: The VYRONAS study. Acta Paediatr. 2009;98(3):495-500, https://doi. org/10.1111/j.1651-2227.2008.01129.x.

This work is available in Open Access model and licensed under a Creative Commons Attribution-NonCommercial 3.0 Poland License - http://creativecommons.org/ licenses/by-nc/3.0/pl/deed.en. 